\title{
金夙中的內耗
}

\author{
葛庭燧 \\ （中國科照院金圆研究所）
}

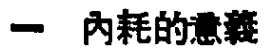

固體在振動中時, 即便是很好地和它的周湋 隔絕起來，它的振動也會泍漸趋於停止，也就是 它的振動能漸漸消耗, 這種內在的能量消耗叫做 內耗。內耗的產生是由於物體的振動引起了队部 變化, 而逼種內部變化引起了振動能的消耗。關 於這種內部戀化的物理機構留待後面討論具體問 題特再談, 現在可以先從現象上來討論內耗的一 般原因。令物體振動時, 應力是作週期性變化 的, 因而所引起的應變也作週期性變化。如果㯰 振動是完全彈性的, 那㦄應力不但與應變成正 此，並且應變是應力的單优函數。在這種情形下，

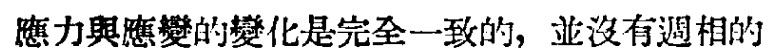
美異，因而並不引起內耗。但是如果物體的振動 引起了某種內部變化, 例如原子的要動, 而這種 內部變化足以使應變落後於應力的話, 那愳由於 應力與應變有了週相差, 就會有內耗産生。我們 可以用二者的週相䔄來衡量內耗的大小，週相琹 愈大則內耗忞大。

內耗的形式和種類是多椂化的。現在所介紹 的是彈性內耗，是當應力極低時所產生的。這時 踓然有應變落後於應力的現象, 但是物體却並不 因此而弦生永久形變。造種彈性叫做㴆彈性, 浫 彈性就是物筫所具有的那種足以引起彄性內耗的 殿性。

我們可以從討論衆所周知的“彈性後效”出

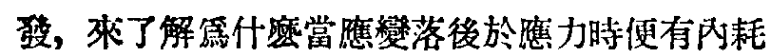

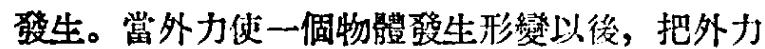
撤去, 如果逪物體並不立即恢復而却是慢慢地恢 復到原來的形狀, 這種情形便叫做彈性後效, 即 隹變落在應力之後。同樣的道理，當我們加力到
物體上時，如果物體並不是立即達到而却是慢慢 地達到它應有的伸長, 造也是應變落後於應力的 一種情况，叫做彈性蛅變。圖 1 是彈性嬬變和彈

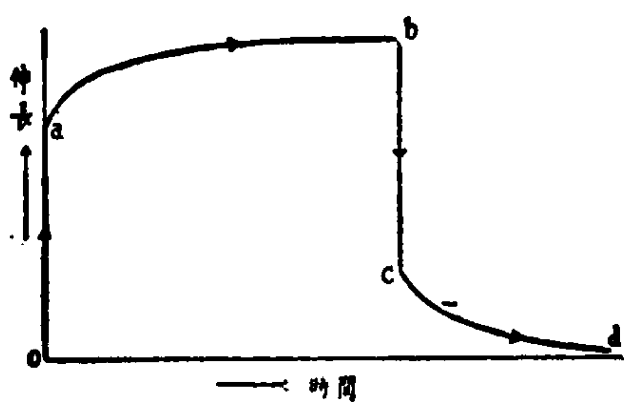

国 1 彈性蠕器和彈性後效

性後效的示意圖。圖中的 $o a$ 表示加力時的显時 彈性伸長, $a b$ 表示彈性䗆變伸長, $b c$ 表示外力 撤去後的僢時彈性回復, $c d$ 表示彈性後效回復。 圖 2 表示完全彈性特的情形。

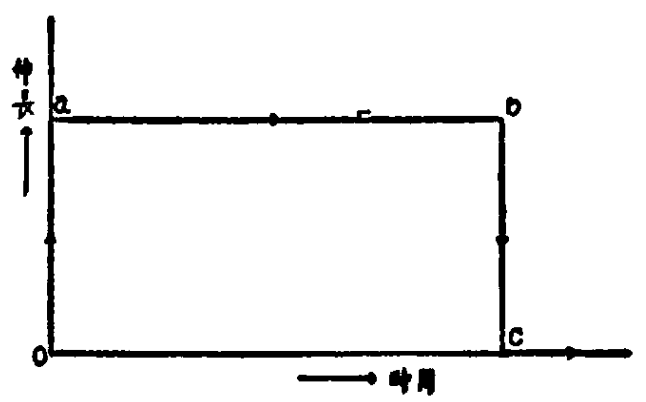

国2 完全筬性時的伸長和回得

物體如果在静力的作用下有彈性蝶變和彈性 後效㟋生, 則令這物娟作彈性振動時便引起內 耗。我們可用圆 $3 a$ 所示的振動嘲, 就如同 在監 速質驗中所用的縱振動金屬积作例子。常週期性 應力作用到捍上時, 稈由平衡位置 $O$ 起始振動。 在經過某一㭙算後應力變䍃零。但因應變較應力 第落後, 此時挏有韸餘應變 $O A$ 存在(見圖 $3 \mathrm{a}$ 及 
3b), 必須應力的方向反轉過 以後, 應綮方逐漸地變篇零, 逻時應力和應變的方向相反, 顯然要引起能量的消耗。

由以上的討論, 可見彈性 內耗只是由於為變落後於應力 而引起的各種表現之一。其它 種的表現，除去彈性䌮變和彈 性後效以外, 還有應力弛预, 即當應變保持在一定數做時物

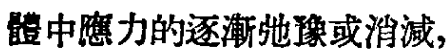
以及動力彈性模量的隨頻率或 温度之不同而戀化等現象。這 些相關的浫彈性現像都可以按

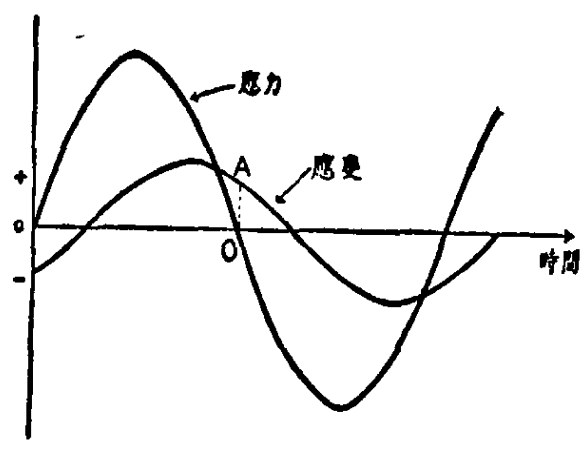

圆 3b 僬笾落後於鷹力時的情形

照一定的公式相亚換算，因陑我們可以根嵻筫驗

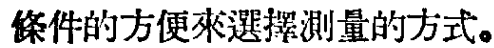

\section{二 内耗䇏}

彈性內耗的特點之一是有內耗峯的出現。把 內耗表示䈍振動頻率的函數時, 內耗之值始而增

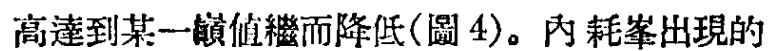
原因是由於物體發生內部變化時具有一定的弛 豫時間。物體在應力的作凩下，第要保持它的位

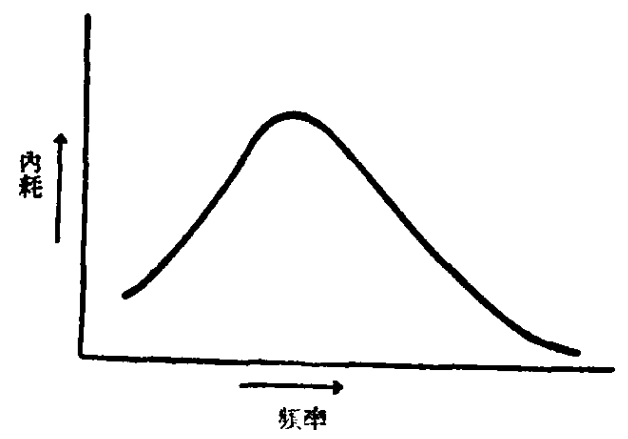

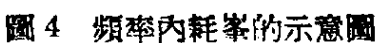

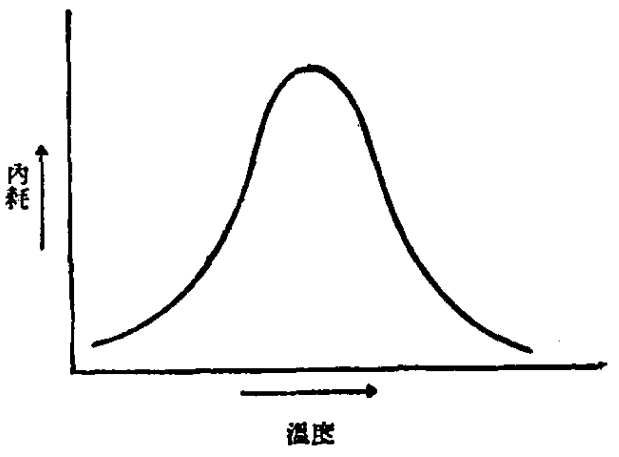

圆 5 温度內耗等的示澺回

能或自由能最低，而由一個平衡態變換到另一 個平衡態，造種本衡態的變換是需要一定時間 的，弛觻時間就表示所需時間。關於弛像現象的

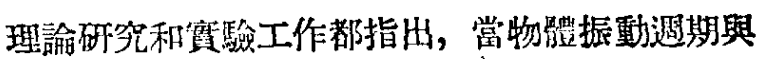
弛䇦時間美不多相等時, 則內耗達到最大倠。由

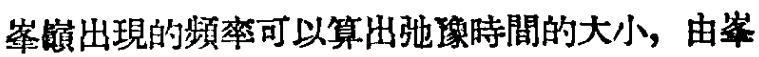

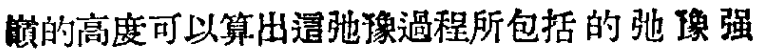
度。

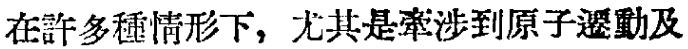
其有關現象的情形下, 弛解時間與試驗温度有一

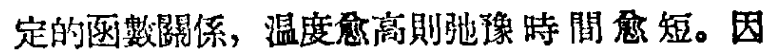
此，在觀測內耗峯時不必變動物體振動的頻率， 只需改變試㮈的温度。逭樣。當驰渒時間由於温 度的改變的變得與振動週期時間相登不多時, 便 也得到一個户耗学。這便是温度內耗淘(見圆 5)。

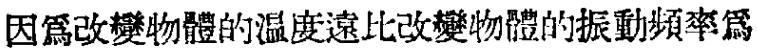
容易, 所以近來關於內耗的測量大都是改督試樣 的温度，而所指的內耗穼一般是温度內耗客。

圖 5 所示的內耗客是用一程:振動頻乲所測出 來的。如果換用另一種頻率隶测量，則整個的內 耗峯便向高温移動（用較大的振動頻率時）或向 低温移動（用较小的振動頻率特）。根據內耗䋆 移動的數值, 可以算侍這弛豫現象中的基本過程 所包括着的激活能。激活能代表金屬原子由一個 平衡態變換到另一個平衡態時所必須克服的位能 量，這一個物理量在金屬結構、絬構變化及原子 䆡散的問題上具有重姴的意義。

\section{三 測量內耗所用的装是}

测量內耗所常用的簡單徒置是扭推。圖 6 是 扭㨢的示意圆(5)。圖中的 $F F$ 是無磁場電嘘, $T$ 是测量温度的熱電偶。試核 $W$ 被外所 $P_{1}, P_{9}$ 


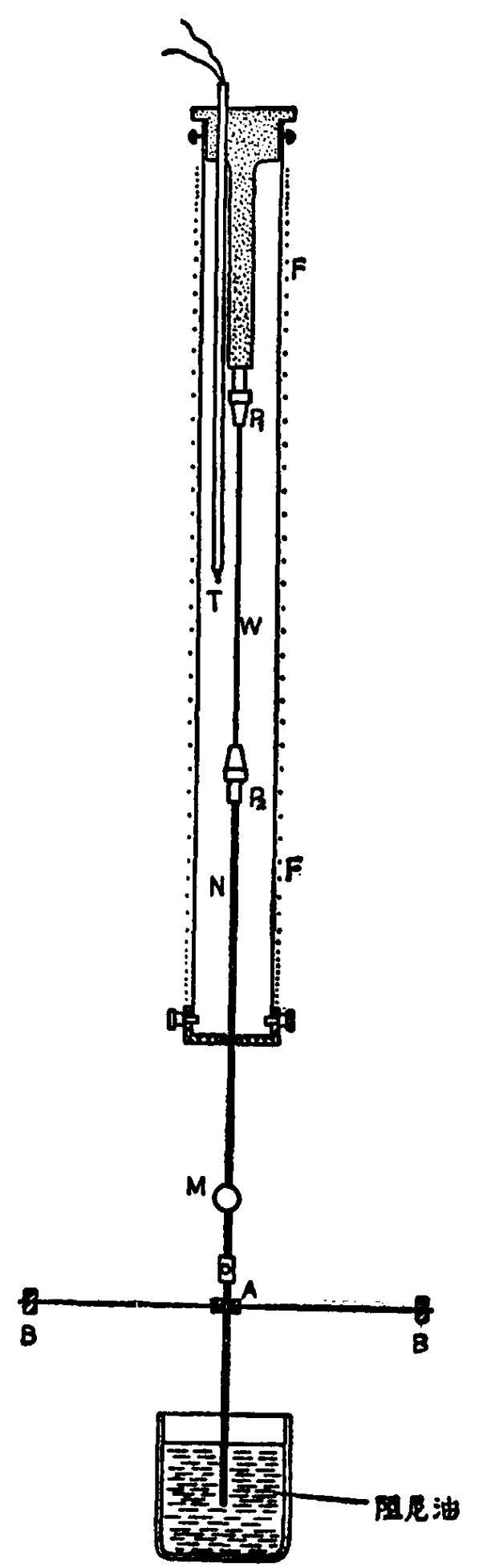

国 6 扭搌

夾緊，䜿固在電㠊的上端。試模的下端連着不銹 鋼桿 $N$, 捍的下部在 $A$ 處套着一個慣量横桿, 橫桿的兩端荷着重量 $B 、 B$ 。第了能够用電磁鐵

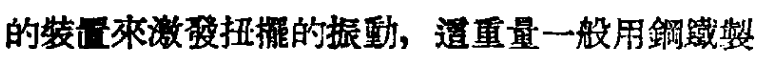
成。調敌造重量的大小或横桿之長，可使振動的 頻率約第每秒一次。連得上遠装伴着一個凹面反
射鏡 $M$, 造樣便可以利用一套燈尺的装 置, 覞 測試樣在自由振動中所發生的衰娍。

如果起始测量時在標尺上所讀 到的 㣂 轎是 $A_{0}$, 振野過 $n$ 次以後的偏轉是 $A_{n}$, 那悹在白由 害堿中的對數減樎量便是

$$
\delta=\frac{1}{n} \ln \left(A_{\circ} / A_{n}\right)_{3}
$$

由理諭的推算可知，虽內耗之侻不大時，內耗等 於 $\delta / \pi$ 。

當應力很小，即在振動中的偏轉之值 很 小 時, 所得的對數減縮量在正常的情形下與㣂轉的 大小無關，也就是說，所測得的內耗之値與 應 力的大小無關。通種性質是彈性內耗的一個特 點。

用扭撤作內耗测量時，試樣各部分上的應力 是不均匀的, 因而在試樣各部分所引起的應變也 不均匀。但是當應力很小時, 應力與應變都適合 於叠加原理, 因而所得的結果和應力與憵變均匀 時相同。

\section{四 用內耗方法作金成研究}

金屬中的內耗既因金屬中所生的內部變化 而起, 所以根據內耗测量所得的結果可以推知金

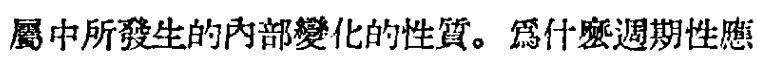
力會引起金屬中的內部絃化呢? 䈍什㦄造種內部

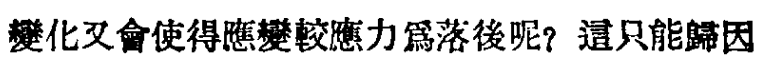
於金屬內部結構的特點。一般而言，凡是金属晶 體中有缺陷存在，或者金屈的結構中有不對䊈的 情况, 在適嘗的條件下都會由於極小的應力而引 起原子的僄動。原子的僄動又轉而引起晶體中的 畸婪或應變, 造成應變較應力第落後。因此, 關 於內耗的砰究不但可以推知金屬及合金中晶體

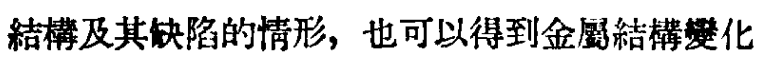
及原子掋散的知䪭。我們都知道，金相㙷微鏡 和 X 射線晶體分析法是作金屬研究的重要工具, 但是它們所能够告訴我們的，在一般的情况下只 是金屬在静態中的情形，而內耗测量則能够告訴 我們金屬在動態中，例如原子在遷動時的情况。

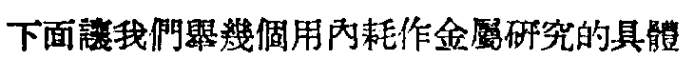
例子。

1. 鋼鐵中的原子蜜散: 冶金上的許多重要

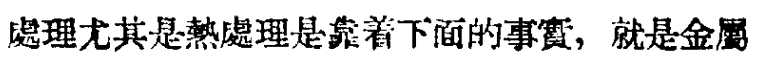




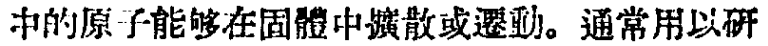

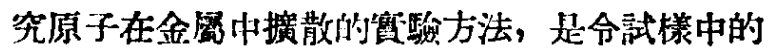

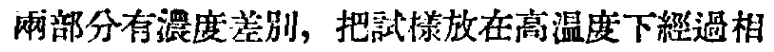
学的時間，然後再符化學分析或其他方法测定試 樣中各地區的湿度, 這情便可以算出來原子的控 散係數。誴種賽驗方法所能够研究的只是大區域 內的据散, 必須在高温度下作長特間的賽驗, 因 面限制了它的應腈簤圍。

閔內耗测量的方法能够，在若干程情形下研究 單僻原子在晶體中跳動的情形。由於跳動或拱散 的距雄很短, 所以觀測的温度可以很低, 而觀测 叮㭙間也可以很短, 因而能够測定在較低温度下

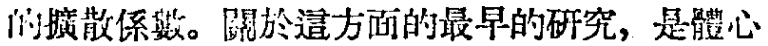
立方系的践中含碳或氮所引起的內耗峯(6)。在體 心鐵中，碳原子（或氮原子）所佔據的是間隐位 圆，圖 7 中所示的是間隙位圆的一種。碳原子佔 據造種間岎位置時，在鐵的晶體點陣中所引起的 彈性睮變是不對稱的。在垂直方向或 $Z$ 方向所引 起的畸變比 $X$ 和 $Y$ 兩方向的大, 因第碳原子與 $Z$ 方向上下雨偑鐵原子的距離較小（見圖中所示 的數字)。還種間知位置可以叫做 $Z$ 位置。碳原 子所能够佔據的間粡位 置除去圖 7 中所示的 $Z$ 位置以外，還有 $Y$ 位置和 $X$ 位置。在 $Y$ 位置

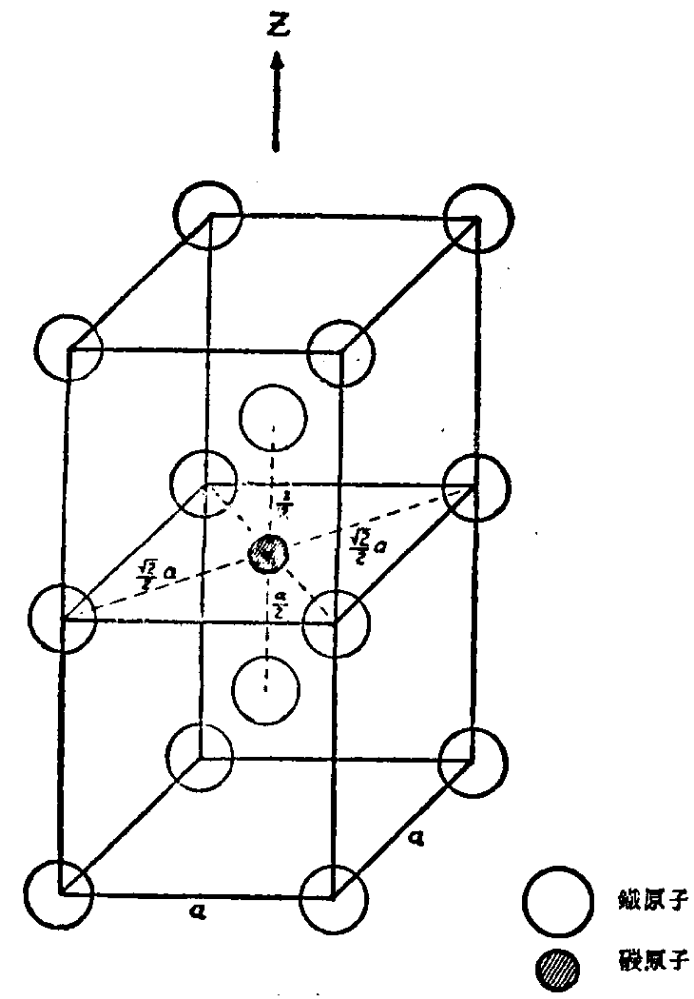

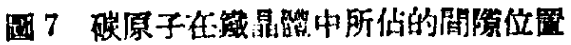

时，沿着 $Y$ 方向所引起的畸较较大，在 $X$ 位置時 則沿着 $X$ 方向所引起的畸變較大。如果没有外力 加到鐵試樣上, 則碳原子佔㨜 $X, Y, Z$ 三種位置 的機會相等。但是如果我們沿着 $Z$ 方向办拉力, 则本來在 $Y$ 和 $X$ 位置的碳原子健有一程要跳㺫

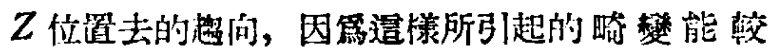
低。闹樣的道理, 如果沿 $Z$ 方向加㩐力, 則本隶

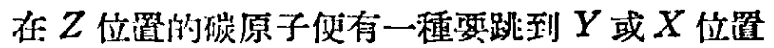

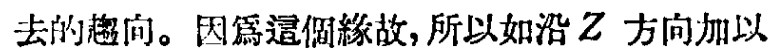
忽拉忽壓的力, 則碳原子即在晶體點陳中往復跳

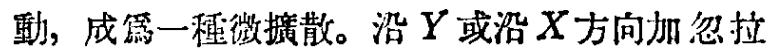
忽原的力時也是如此。原子的跳動需要一定時 闆，所以由於原子的跳動而在晶體點陣中所引起

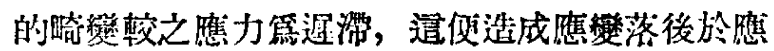

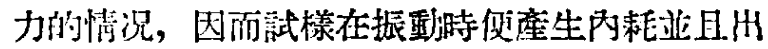
現一侧內耗案。

隨後的蒉驗指出㯰種理諭適用於一切體心江 方系鼠體所形成的填隐式固溶體，因第類似们队

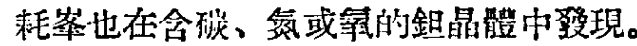

上述的現象已絁被應用到詐多䅜金屬研究，

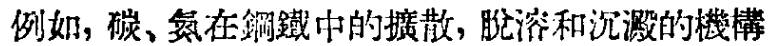

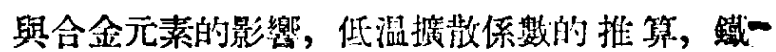
碳及鐵一第平衡圖中初級固溶體相界的测定。上 速的理論也已經被推廣到面心立方系替代式固溶 䋨如 $C u-Z n$ 和 $A g-Z n$ 系統中的原子微拱散。

我們最近閣於這方面问的內耗呼究工作更進一 步地指出，藍脆的現像是鋼中的碳或筮以原子狀 態脫溶到鋼中的加工缺陷或淬火內應力區域所引 起，而回火脆則是一種退火沉搌的過程，產生回 火脆的因素可能是沉澱出來的氛化物而不是碳化. 物。

上面所說的僄種內耗的應用只限於體心立才。 系的埕鐵中的間隐原子振散，我們最近又在幾種 面心立方系的鎆中觀測到因含碳而引起的队耗 峉。關於激活能的測量指明这內耗峯是由於碳在 面心立方系的昆體點陣中的擴散, 而且队耗峯的

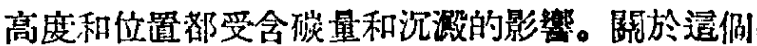
內耗窅的機構現在踓然還没有確切的了解，但是

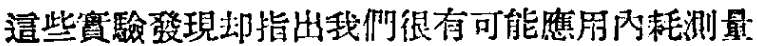
的方法來研究碳（或氮）在面心立方系的针润（做

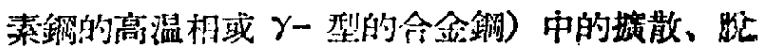

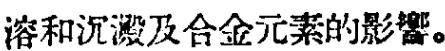


2. 金易中晶粘間界的力學性質：金盛材料 的最重要性䝷是它的力學性質。因篇一切的筫在 金屬都是由部多小晶體組合而成的，所以要了解 金屈的力學性質，不但要了解每顆小晶體本身的

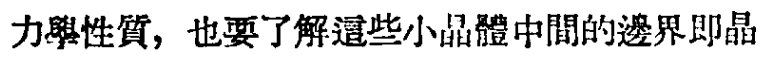
和間界的力㦛性質。向來關於晶粒間界的力㠘性 啠只有一些不確切的定性的看法, 由於一系列的 队耗研究才定量地指明了晶粒間界具有粘覆性 啠(5)，型且求出了數種金屬和合金中的晶粒間界 的粘帮係數及其因温度而變化的数量關係。

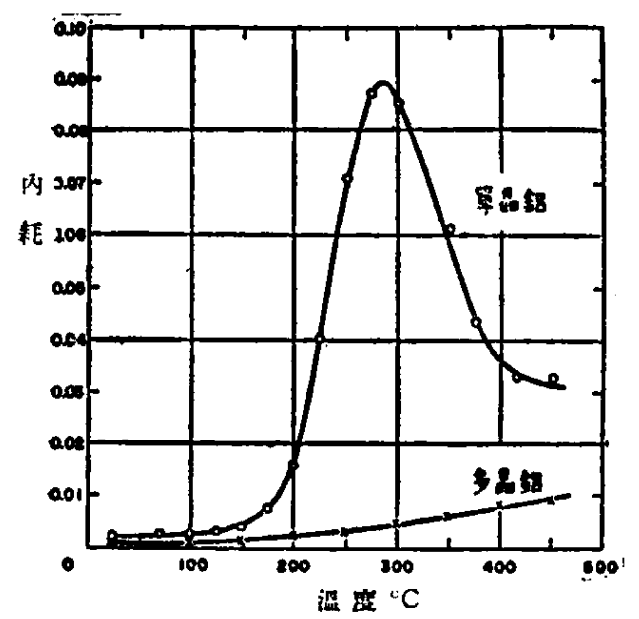

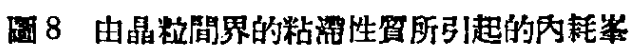

最初用內耗方法研究晶粒間界的力學性質的 工作是用純颌作的。圈 8 表示多晶鋁與單晶鋁的 內耗隨温度而攀化的情形, 测量內耗所用的振動 频率約䈍每秒一次，在多晶鋁的情形有一话內耗

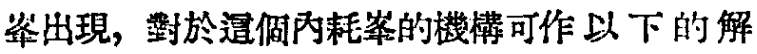
釋。

虽外力加到多晶鋁的試樣上時, 侹有一種切 隹力作用到晶粒間界上如圖 9 所示。由於昆粒間

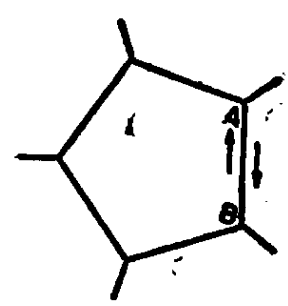

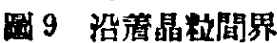
的粘消珄滑移
界具有粘潭性罂，不能够芰 持切應力, 所以梴發生一檑 沿着昆粒間界的粘憡性滑 移。昆粒間界的交角對於造 程滑移具有一種的制的作 用，使遭滑移達到某一程度 後侹於停止。這程因外皮 力而引起來的粘㠿滑移便造成一種應變落後於㷪 力的情况，因而在振動時座生內耗。造內耗的 大小是由滑移距離與滑移阻力二老的乘棹來决定 的。在温庭很低封, 由於鼠粒間果的粘浫係数很
高, 所以在一定時間內由於一定的外加力所引起 的滑移距離很小，内耗地很小。始温度很高時，

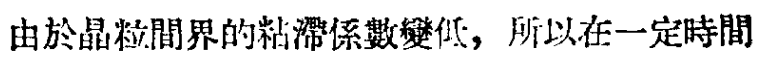
內滑移一定距離（因爫受到鼠粒間界交角的約 制) 所遭遇到的滑移阻力很小，因而䧄耗又很

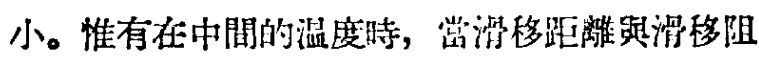

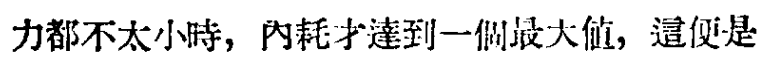
有一佪內耗条出現的原团。

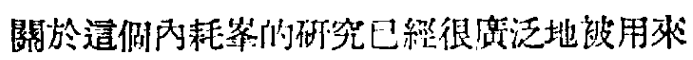

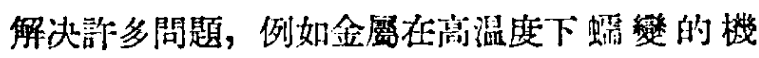

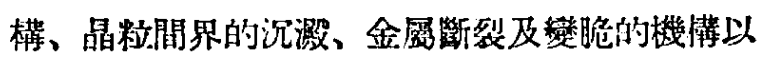
及晶粒長大問題。關於晶粒間界粘㵊滑移激活能 的测量, 更能够提出来一㑑昆䊉間界結櫵的空公

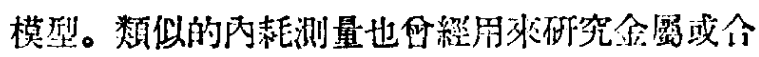
金中各種不連續間咱面的力學性篗。

最近我們關於造方矿的研究指出，在紝鐵中 加碳少到 $0.0001 \%$ ，已䌊足以使晶糕閏界的粘漈

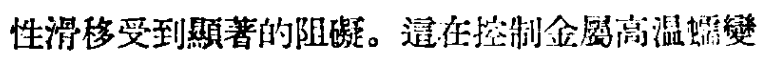
的問题上指出了一倨一般性的原则，都於品粒間

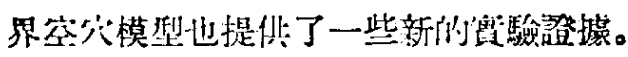

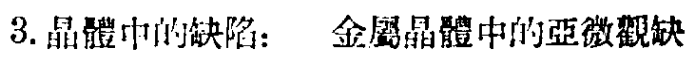

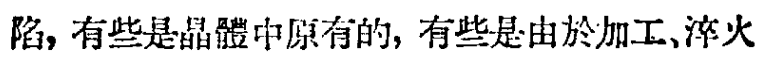

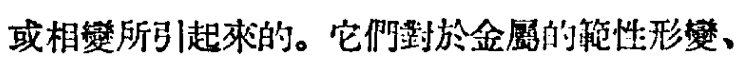
断裂以及合金中的窝散及相變都具有極大的影 響。目前討論得最多的昆體缺陷是原子脱䈟和空

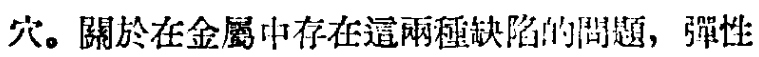

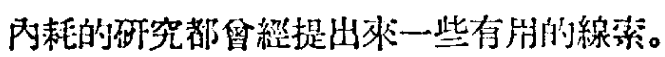

原子脫節的模型踓然已經很廣泛地被用來解 釋詐多種昆體範性形變的現象，但是金屬中究竟 有没有原子记䬣的存在, 却没有確切斷然的澄 據, 關於遙犅問題現在最需要的是一些有判断性

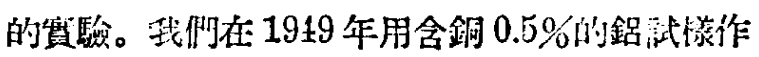
內耗测量時, 發現試愫在泠加工並經過適當的退 火以後有一種反管的內耗發生。即在一定们觀测 温度, 如將內耗表示笞應力的函數, 则得到一偑

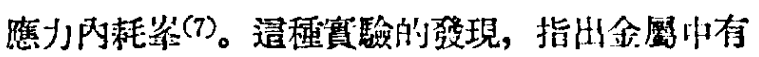
原子胫節存在。鉊試樣中团加工而成生的這種原 子汒節與銅原于結合成此較硕定的集園, 㯰種集

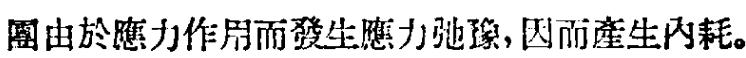

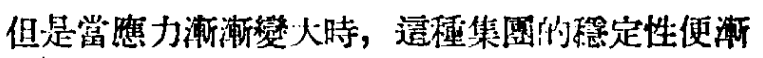

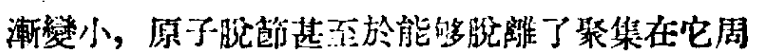
圍的渗算原子而自由遇動，网而队耗双由於應力 
的增加而降低，引起了反常的队耗。

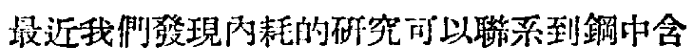
受髹裂的問題。過去的研究雖然已經指出鋼中的

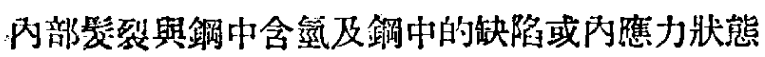
有關係，但是關於引起內部琴裂的機構則還没有 明確地了解。我們最近根據內耗的測量發現含鉻

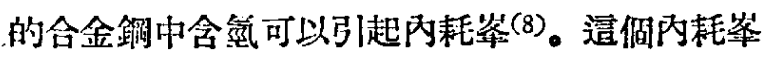
受冷皮工和保温處理的影響, 由此可以推知罯佪

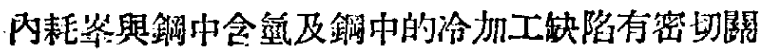
係。又因篇所測得的內耗峯表現有一種反常的振 幅效應（在温度一定時可得應力內耗崒如 圆 10 所示)，與上迅在鋁銅合金中所發現的反 常內耗

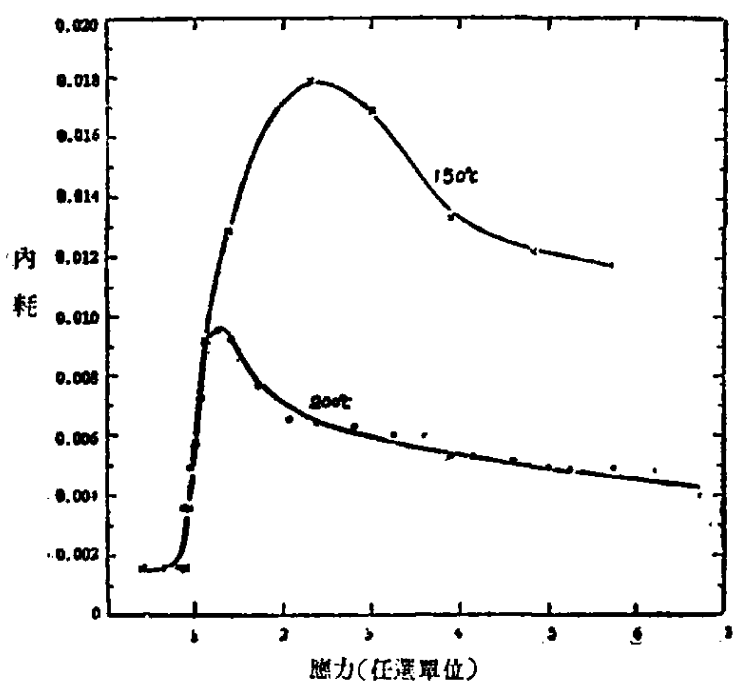

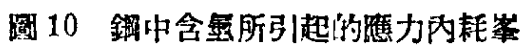

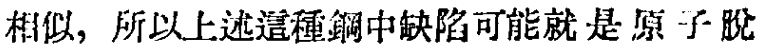

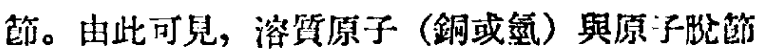
（鋁或䍸中所含的）交万作用的現象可能是一種 普掘的現象。一般的研究原子睦簛的方法都是公 觀的，而內耗的方法却可以㙷示金屬中的單假的 原子㧤節在自由狀態時及與溶質原子發生交石作

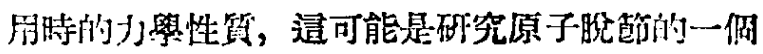

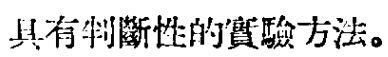

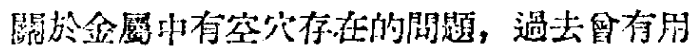
队耗方法在活心立方系替代式固溶體 $A g-Z n$ 中 所作過的微窝散實驗。最近我們發現了純䤼（㓦 心立方系）中含碳可以引起內耗崽, 關於激活能

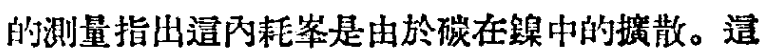
種由於微憵力而引起的在面心立方系的點阵中的 間隙式摭散可能與晶體點陣中所存在着的空穴有 關係。

4. 金虽與合金中的相變: 用內耗方法來湖 究金屬與合金中的相變，是一個新近開閣的領 域。過去在譄方面僅有一些關於记溶和沉激的例 究。我們最近發現馬氏體在回火轉綡中引起一個

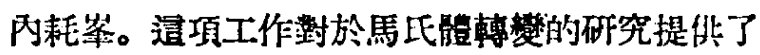
一個有力的工具。

以上所介紹的四值方面並不足以包括用强性 內耗所能够解决的一切問題, 其它方百㮣該特别 提出的還有熱彈性》耗及磁致件縮所引起的內

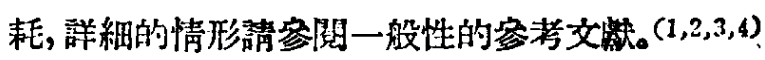

\section{等考文}

一般性的:

(1) C. Zener, Elasticity and Anelasticity of Metals (University of Chicago Press, Chicago, 1948).

(2) Сборник, Упругость и Неупругость Металлов (Издатөльство иностранной литературы, Москва, 1954).

(3) A. S. Nowick, Internal Friction in Metals, article in Progress in Metal Physics, Vol. IV (Pergamon Press, London, 1953).

(4) В. С. Постников, Рөлаксационные явления в металлах и сплавах подворгнутых дөформированию, Успехи физических наук 53, 87 (1954).

專題研究的:

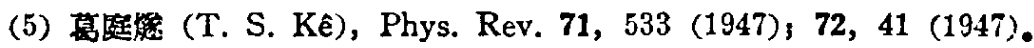

(6) J. L. Snoek, Physica 8, 711 (1941)。

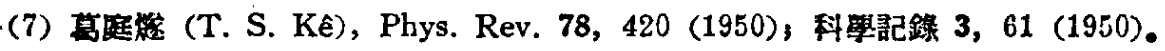

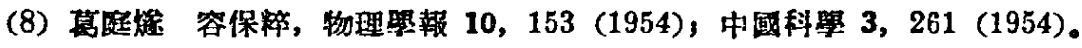

